\title{
SMARCA4 Gene Inactivation
}

National Cancer Institute

\section{Source}

National Cancer Institute. SMARCA4 Gene Inactivation. NCI Thesaurus. Code C138016.

A mutation in the SMARCA4 gene that either inhibits expression of the SMARCA4 protein or results in the translation of an inactive SMARCA4 protein. 